\title{
PENGARUH TINGKAT SUKU BUNGA SERIFKATBANK INDONESIA TERHADAP PERUBAHAN NILAI TUKAR (KURS) RUPIAH ATAS DOLAR AMERIKA: GRANGER CAUSALTASTEST
}

\author{
Ferdinandus Stenly* \\ Fa kulta s Ekonomi Universitas Pattimura
}

\begin{abstract}
The Bank of Ind onesia Certifica te is one of monetary instruments that used by govemment to influence IDR Exchange Rate Movement Over USD. The purpose this research is to obta in the describe more detailed about influence Certificate Bank of Indonesia toward an IDR Exchange Rate Movement Over USD which try to give an information in a common manner to be concemed outsider espacially relate to govemment policy. This research using the secondary data with limit that analysis duning 20 months that are from November 2005 to June 2007. In compile this thesis, the author camy out the causality relationship analysis (causality) with Granger Causa lity Test (GCT) and relationship closeness a nalysis which using Ordinary Least Square (OLS) regresion analysis. The Granger Causality Test (GCT) analysis result explains that from a nalysis result obtained as model considered valid is the rate interest of SBI has influence toward an IDR Exchange Rate Movement over USD. This was proved on GCT test too much significant for $Y=f(x)$ and not on contary $X=f(y)$. The a nalysis result of Ordinary Least Square (OLS) was obtained $F_{\text {test }}(2,18)$ is $266,081>F_{\text {table }} 6,01$. This means as variable an independent influence variable dependent. Beside that was obtained test $16,312>$ trable 2,21009 that mean the rate interest level of SBI has the influence signicant toward an IDR Exchange Rate Movement Over USD. Because the Certificate of Bank of Indonesia has negative influence towards IDR Exchange Rate Movement Over USD, the author suggests the Indonesia Govemment to defend and to optimalyze the existing instrument, so that the monetary condition is more controlled and the stability can be maintained.
\end{abstract}

Key Words: Rate interest level of SBI, IDR Exchange Rate Movement Over USD, Ordinary Least Square (OLS), Granger Causa lity Test (GCT). 


\section{PENDAHULUAN}

Pada permulaan tejadinya knisis di Indonesia jumlah uang beredar di Indonesia sangat fluktuatif. Hal itu disebabkan oleh semakin melemahnya nilai tukar Rp terhadap USD, yang memicu kenaikan harga-harga barang berbahan baku impor, sehingga kebutuhan akan rupiah menjadi lebih besar untuk melakukan transaksi sebagi akibat tingginya kenaikan tingkat harga tadi. Terlihat dalam beberapa tahun terakhir, perekonomian Indonesia telah mengalami perubahan yang cukup mendasar. Kebijakan pembangunan sektor ekonomi merupakan perhatian yang lebih dibandingkan sektor-sektor lainnya. Tenutama sektor keuangan, diharapkan mampu memperlancar dan meningkatkan efesiensi pengalokasian sumber daya yang pada gilirannya telah mendorong kegiatan perekonomian secara berarti. Dipihak lain, perkembangan tersebut menimbulkan tantangan bagi pengendalian moneter di Indonesia.

Telah berbagai cara ditempuh oleh pemenintah untuk menstabilkan kembali nilai tukar, salah satunya cara yang ditempu yaitu dengan mepenetapan suku bunga SBl agar menarik jumlah uang beredar yang ada di masyarakat. Peningkatan jumlah uang beredar menupakan dampak dari arus modal masuk dalam beberapa ta hun terakhir perkembangan tersebut apabila tidak diwaspadai dapat memicu pemanasan suhu perekonomian. Indika tor pertama yang dapat dilihat adalah tingkat bunga. Tingkat bunga mempunyai arti penting dalam mengendalikan stabilitas ekonomi oleh karena itu tingkat bunga harus dibentuk sedemikian rupa agar berdampak positif pada perekonomian secara keseluruhan.

Bank Indonesia selaku otoritas moneter terus melakukan intervensi yaitu campur tangan dalam mengatur perekonomian yang bertujuan untuk meningkatkan efisiensi suatu sektor tertentu melalui pengelua ran kebijakan moneter dan fiskal, Bank Indonesia telah melakukan berbagai langkah antara lain menetapkan suku bunga SBI dengan harapan melebarkan intervensi dan pengetatan likuidasi. Namun upaya tersebut belum menunjukkan hasil yang diharapkan. Kemerosotan dan gejolak nilai rupiah terus berlanjut yang berdampak pada inflasi, sementara kepercayaan investor terhadap kemampuan pengelolaan dan prospek ekonomi semakin berkurang.

Situasi ini semakin diperburuk dengan krisis kepercayaan masyarakat terhadap perbankan nasional. Krisis ini mendorong masyarakat untuk menarik dana secara besar-besaran, memindahkan simpanannya dari bank yang lemah ke bank yang kuat a tau menggunakan dananya untuk membeli valuta asing. 


\section{Permasalahan Penelitian}

Masalah yang ditemui sesuai dengan latar belakang diatas yakni ; sejauhmana pengaruh tingkat suku bunga Sertfikat Bank Indonesia terhadap penubahan nilai tukar (kurs) Rp atas US \$ (J anuari 2006 - J uni 2007) dengan pendekatan Granger Causalitas Test Dan Ordinary Least Square.

\section{Tujuan Penelitian dan Manfaat Penelitian}

Tujuan dari pada penelitian adalah untuk mengetahui penganuh tingkat suku bunga Sertfikat Bank Indonesia terhadap perubahan nilai tukar (kurs) Rp a tas US \$ (J a nuari 2006 Juni 2007) dengan pendekatan Granger Causalitas Test Dan Ordinary Least Square.

Sedangkan Penelitian ini diharapkan dapat memberikan manfaat:

1. Secara akademik, hasil penelitian ini diharapkan bisa menjadi masukan bagi perkembangan teori tentang pasar keuangan (financial market) khususnya tentang pasarvaluta a sing di Indonesia.

2. Bagi peneliti, dapat memberikan tambahan wawasan dan mengembangkan ilmu pengetahuan yang telah diperoleh, khususnya, Ekonomi Intemasional, Manajemen Keuangan Intemasional. Dan Manajemen Derivasi.

\section{TINJ AUAN PUSTAKA}

Tingkat bunga adalah harga dari penggunaan uang atau bisa juga dipandang sebagai sewa atas penggunaan uang jangka waktu tertentu. Harga ini biasanya dinyatakan dalam presentase persatuan waktu. Fungsi tingkat bunga didalam suatu perekonomian adalah sebagai pengalokasian faktor produksi untuk menghasilkan barang dan jasa sekarang yang dipakai dikemudian hari. Jadi tingkat bunga juga menupakan fungsi altematif dalam perekonomian khususnya dalam pengunaan uang a tau modal. (Boediono, $2001 ; 75$ ).

Teori paritas tingkat bunga adalah sala satu teori penting mengenai penentuan tingkat bunga dalam sistem devisa bebas (yaitu a pabila penduduk masing-masing negara bebas memperjua lbelikan devisa). Teori ini pada pokoknya menga takan ba hwa :

Dalam sistem devisa bebas tingkat bunga dinegara satu akan cedenung sama dengan tingkat bunga dinegara la in, setelah diperhitungkan pikiran mengenai laju deperesiasi mata uang negara yang satu terhadap negara yang lain (Boediono, $2001 ; 101$ ).

Atau secara aljabar,

$$
\mathrm{Rn}=\mathrm{Rf}+\mathrm{E}^{*}
$$


Keterangan; $\mathrm{Rn}$ : tingkat bunga (nominal) di dalam negr

Rf : tingkat bunga (nominal) di luarnegri

E* : laju depresiasi mata uang dalam negri terhadap mata uang asing yang diperkirakan akan terjadi.

Sejak di gulirkannya deregulasi dibidang moneter dan perbankan, dimana bank-bank diberi kebebasan yang lebih besar untuk menetapkan sendir kebijaksanaan dibidang kredit, dana, dan dalam penetapan suku bunga. Sementara itu, Bank Indonesia hanya menyediakan kred it likuiditas untuk sektor-sektor berprio ritas tinggi. Oleh sebab itu sejak saat tersebut Bank Indonesia dalam rangka pengendalian moneter menggunakan kebijaksanaan moneter tidak langsung yaitu : likuid itas wajib minimum (reserve requirement), operas pasar terbuka (open market policy), dan fasilitas diskonto (dinscount windows). Operasi terbuka adalah proses pembelian dalam penjualan surat-surat berharga dipasar uang (SPBU) oleh Bank Indonesia dengan tujuan mempengaruhi jumlah uang beredar dan tingkat bunga di pasaruang. Untuk pelaksanaan operasi pasar terbuka digunakan SBI untuk kontraksi moneter dan SPBU untuk ekspansi moneter. Penjualan SBI dilakukan melalui lelang harian dan diadakan sesuai dengan kebutuhan dalam rangka pengendalian keadaan moneter. Sela in sebagai piranti operasi pasar terbuka, SBI juga dipakai sebagai pengganti surat-surat berharga yang tidak diperdagangkan oleh Departemen Keuangan.

Dengan melalui SBI tersebut Bank Indonesia secara tidak langsung dapat mempenganuhi suku bunga dipasar uang dengan jalan mengumumkan Stop Out Rate (tingkat suku bunga diterima oleh Bank Indonesia atas penawa ran tingkat suku bunga dari peserta lelang harian maupun lelang mingguan). Selanjutnya Stop Out Rate tersebut diharapkan dapat dipakai sebagai indikator bagi tingkat bunga transaksi dipasaruang pada umumnya.

Tingkat bunga tinggi akan mendorong masyarakat konsumen menabung dan menginvestasikan kelebihan dana yang dimilikinya daripada digunakan untuk konsumsi sekarang. Apabila konsumen mengharap barang dan jasa yang lebih baik dari sejumlah uang pada masa yang akan datang, maka keputusannya adalah menabung. Menurut ekonom klasikal, bunga menupakan suatu altematif dari berbagai pilihan untuk mengoptimalkan uang, antara lain dapat investasi ke pasar modal, atau menabung dengan tingkat bunga tertentu. Semakin tinggi tingkat bunga, akan semakin tinggi pula tabungan, dan sebaliknya. (D. Martin2004;13). 
Menurut Betty J ane Punnet memberi pengertian pasar valuta asingsebagai berikut ; foreign exchange market is the place for foreign currencies convertion. Foreign currency is the currency of other countries" (Kurgman $2003 ; 313$ ).

Menurut Sadono Sukimo, nilai (kurs) valuta asing ialah Kurs (exchange rate) adalah harga sebuah mata uang dari suatu negara yang diukur atau dinyatakan dalam mata uang lain (2003; 358). Dalam istilah la in kurs a dalah harga pembelian dan penjualan mata uang asing a ta u klaim atas mata uang asing tersebut. Kurs sangat mema inkan peranan penting dalam keputusan pembelanjaan, karena dengan kurs memungkinkan kita menerjemahkan hargaharga dari berbagainegara ke dalam suatu bahasa yang sama.

Oleh karena kurs harga relatif dari dua a set, maka sangat layak bila kurs dianggap sebagai harga a set itu sendin. Prinsip dasar penetapan harga aset adalah bahwa nilai aset saat ini ditentukan oleh perkiraan daya belinya dimasa mendatang. Dalam mengevaluasi aset, para penabung (investor) selalu memperhatikan aspek perkiraan imbalan (rate of retum) yang dibuahkan aset tersebut, atau tingkat pertambahan nilai investasi yang tertanam dala m a set tersebut di waktu-waktu selanjutnya. Unsur a set yang sangat diperhatikan para investor adalah unsur nilnya (reel rate of retum), ya kni perkiraan tambahan nila i suatu aset dalam ukuran daya beli atau jumlah tambahan output yang bisa diperoleh dengannya. Keseimbangan didalam pasar valuta asing mensyaratkan adanya kondisi interest parity, yakni suatu kondisi di mana berbagai simpanan dalam mata uang apapun menawarkan perkiraan imbalan yang sama besamya (bila diukur/dihitung dengan satuan yang sama).

Faktor-faktor yang mempengaruhi tingkat bunga salah satunya adalah kebijakan pemerintah, dimana penentuan tingkat bunga dari pengendali moneter bias meyebabkan fluktuasi pada nilai tukar suatu negara. Oleh karena itu jumlah valuta a sing yang tersedia di pasar valuta asing terkadang terlalu sedikit pada saat permintaan a ta s valuta a sing (dalam hal ini US \$) tinggi, ini akan mengakibatkan harga (nilai) mata uang dolar meningkat atau mata uang rupiah akan melemah. Melemahnya kurs Rp terhadap US \$ mencerminkan merosotnya term of trade (harga barang dan jasa Indonesia relatif murah dalam US \$) walaupun tingkat harga dalam rupiah tetap. Akibatnya pemintaan barang dan jasa yang dihasilkan Indonesia akan meningkat, sebaliknya pemintaan terhadap barang dan jasa negara Amerika akan menurun. Atau bila semua kondisi la innya tetap, depresiasi mata uang dari suatu negara terhadap segenap mata uang lainnya ( kenaikan harga valuta asing bagi negara yang bersangkutan ) menyebabkan ekspomya relatif lebih murah dan impomya rela tif lebih mahal. (Ahmad J a mli 2004 ; 42). 


\section{METODE PENETIAN}

1. Granger Causa litas Test (GTC)

Uji Kausalitas Granger merupakan metoda penyelesaian terha dap hubungan kausalitas dua variabel, yaitu untuk megetahui apakah sebuah variabel memiliki pengaruh yang bersifat timbal balik dengan sebuah lainnya atau tidak. Uji Granger Kausalitas dinumuskan dengan dua persamaan regresi, yaitu regresi tanpa pembatas (Unrestrected Regression) dan regresi dengan pembatas (Restrected Regression) formula sinya sebagai berikut:

Menguji pengaruh $X$ terhadap $Y$

a. Regresi tanpa pembatas (Unrestrected Regression):

$$
Y=\sum_{t=1}^{p} \alpha_{i} Y_{t-1}+\sum_{j=1}^{Q} \beta_{j} X_{t-j}+\sum t
$$

b. Regresi dengan pembatas (Restrected Regression):

$$
Y=\sum_{t=1}^{p} \alpha_{i} Y_{t-1}+\sum t
$$

Da lam hai ini hipotesis nol yang diuji menyatakan bahwa $X$ tidak mempengaruhi $Y$.

Menguji pengaruh $X$ terhadap $Y$ :

1. Regresi tanpa pembatas (Unrestrected Regression):

$$
Y=\sum_{t=1}^{p} \alpha_{i} Y_{t-1}+\sum_{j=1}^{Q} \beta_{j} X_{t-j}+\sum t
$$

2. Regresi dengan pembatas (Restrected Regression):

$$
Y=\sum_{t=1}^{p} \alpha_{i} Y_{t-1}+\sum t
$$

Da lam hal ini, hipotesis nol yang diuji menya takan bahwa $\mathrm{Y}$ tidak mempengaruhi $\mathrm{X}$.

Untuk menentukan hasil uji mana yang berlaku digunakan uji Wa ld-F yang difo mulasikan (I Gusti Ngurah Agung 2001;50)) sebagai berikut.

$$
F_{h}=\frac{(E S S R-E S S U) /(Q)}{E S S U /(N-P-Q)}
$$

Keterangan :

ESSR = jumlah kuadrat emror pada Restrected Regression

ESSU = jumlah kuadrat emrorpada Unrestrected Regression

$\mathrm{N}=$ Banyaknya pengamatan dimana $\mathrm{N}^{1 / 3}$ jadi $\mathrm{P}=\mathrm{N}^{1 / 3} \mathrm{Q}=\mathrm{N}^{1 / 3}$ 
Kriteria pengujian sebagai berikut :

Bila $\mathrm{F}$ hitung lebih kecil dari $\mathrm{F}$ tabel, maka hipotesis nol tidak ditolak, berarti variabel bebas tidak mempenga ruhi variabel tidak bebas. Sebaliknya, bila $\mathrm{F}$ hitung lebih besar dari $\mathrm{F}$ tabel maka hipotesis nol ditolak, yang berarti variabel bebas mempenganuhi terhadap variabel tidak bebas.

Dengan pengujian tersebut akan dapat diperoleh salah satu dari $Y$, kemungkinan hasilnya sebagai berikut :

a. X mempengaruhi $Y(X-\cdots \cdots)$

b. $Y$ mempengaruhi $X(Y-\cdots)$

C. $X$ dan $Y$ saling mempenga ruhi a tau terjadi penga ruh dua a rah ( $Y \longrightarrow \cdots X$ )

d. X dan $Y$ tidak saling mempengaruhi atau independent ( $X / / Y)$

2. Regresy Ordinary Least Square (OLS)

Analisis regresi adalah studi mengenai ketergantungan suatu variabel tidak bebas (dependen) terhadap satu atau lebih variabel bebas (independent) untuk mengestimasi dan untuk meramalkan nilai rata-rata populasi variabel dependen berdasarkan nilai tetap variabel independent. Untuk mengestimasi fungsi permintaan digunakan metode regresi kuadrat terkecil biasa (Ordinary Least Square). Pada OLS ini akan membahas First Order Test (uji orde sa tu). Dimana uji orde sa tu terd in dari uji signifika si parameter secara individu (uji-t),

$$
t=\frac{b_{i}-b_{i}^{\wedge}}{S\left(b_{i}\right)}
$$

Dimana :

bi $=$ Parameter diestimasikan

$\mathrm{bi}^{\wedge}=$ Nilai hipotesis dari bi

$\mathrm{S}(\mathrm{bi})=$ Simpangan baku

Hipotesis nol yang biasa digunakan adalah : $\mathrm{H}_{0} ;$ bi ; 0

Hipotesis altematif adalah: $\mathrm{Ha}$; bi $>0$

\section{Ufi signifikan parametersecara bersama-sama (uji-f)}

$$
F=\frac{\left(R^{2}\right) /(K-1)}{\left(1-R^{2}\right) /(N-K)}
$$

Dimana :

$\mathrm{K}=$ Jumlah parameteryang diestimasi temasuk konstanta

$\mathrm{N}=$ Jumlah pengamatan 
dan uji keabaian usai (uji-R²).

$$
R^{2}=\frac{\sum Y^{\wedge}}{\sum Y^{2}}
$$

Dimana :

$Y^{\wedge 2}=$ NilaiY estimasi

$\mathrm{Y}=$ Nilai aktual

Sedangkan nilai $R^{2}$ yang disesuaikan (adjusted $R^{2}$ ) yaitu nilai $R^{2}$ yang telah diperhitungkan derajat kebebasan adalah :

$$
\text { Adjusted } \overline{R^{2}}=1-\frac{\sum e^{2}}{\sum Y^{2}}
$$

Dimana :

$$
\frac{\sum e^{2}}{\sum Y^{2}} \text { Adalah variasi yang tidak dapat dijelaskan dari } Y \text { a ktual disekitar } Y \text { estimasi }
$$

rata-rata. Adjusted $\mathrm{R}^{2}$ diperlukan karena masalah yang dihadapi oleh $\overline{R^{2}}$ yakni bahwa penambahan variabel penjelas ke persamaan tertentu tidak akan pemah menunut $\mathrm{R}^{2}$.

\section{HASL PENEUTIAN DAN PEMBAHASAN}

Peneliti akan mencoba untuk menganalisis dan membahas hasil penelitian dengan menggunakan dua alat a na lisis yakni :

\section{Ana lisis dengan pendekatan Granger Causa lity Test (GCT)}

Untuk mengetahui hubungan kausalitas ( $X$ mempengaruhi $Y$ dan sebaliknya $Y$ mempengaruhi $X$ ) antara tingkat suku bunga SBI dengan perubahan nilai tukar (kurs) rupiah atas US \$, peneliti, mencoba menganalisis dengan menggunakan alat analisis model Granger Causa lity Test.

Data yang dianalisis berupa tingkat suku bunga SBI dan perubahan nilai tukar (kurs) rupiah atas US \$ yang telah di translog (transfomasi logaritma) dari periode November 2005 - J uni 2007, Dalam melakukan a na lisis dengan meng gunakan model Granger Causality Test (GCT) 
ini, peneliti mencoba memodifikasikan antara variabel dependen dan variabel independent agar diperoleh peritungan yang signifikan. Pengujian dilakukan dengan mengguna kan dua model ya kni ; model $X$ terhadap $Y$ dan model $Y$ terhadap $X$, dimana $X$ merupakan tingkat suku bunga SBI (Sertifikat Bank Indonesia), Y merupakan perubahan nilai tukar (kurs) rupiah a tasUS\$.

Pada model 1 perubahan nilai tukar (kurs) rupiah atas US \$ (X) sebagai variabel independent yang mempenga ruhi variabel Y yakni perubahan nilai tukar (kurs) rupiah atas US \$ sebagai variabel dependen, dan model 2 variabel $Y$ yakni perubahan nilai tukar (kurs) rupiah atas US \$ sebagai variabel independent yang mempengaruhi variabel $X$ yakni tingkat suku bunga SBl sebagai variabel dependen. Dari kedua model diatas dilihat model mana yang lebih banyak signifikannya, sehingga membuktikan ada tidaknya hubungan kausalitas (timbal balik) diantara variabel-variabel yang diteliti. Kuat atau lemahnya hubungan tersebut akan ditunjukan oleh besar atau kecilnya ratio hubungan ( t-ratio). Berikut ini ha sil perhitungan dengan menggunakan model Granger Causa lity Test (GCT).

Berdasarkan hasil pengolahan data dengan menggunakan software Statistical Package for Social Science (SPSS) pada metoda Granger Causa lity Test (GCT) untuk model pertama $\mathrm{Y}=\mathrm{a}+\mathrm{bX}$ adalah seperti yang tercantum pada tabel dua dibawah ini :

Tabel 1 : Hasil Pengolahan Model 1 GCT

\begin{tabular}{|c|c|c|c|c|}
\hline & $\begin{array}{l}\text { Dependen Variabel } \\
18 \text { observation used }\end{array}$ & mation & $\operatorname{lan} 2006 t$ & ก. 2007 \\
\hline & Regresor & & & $\mathrm{t}$ - ratio \\
\hline & $\mathrm{X}$ & & & $-2,535$ \\
\hline & Y2 & & & 204,058 \\
\hline & $\mathrm{X} 1$ & & & 0,974 \\
\hline & $\mathrm{x} 2$ & & & 2,737 \\
\hline & Y1 & & & 0,782 \\
\hline & $\mathrm{R}$ & 1,000 & S.E. & \\
\hline & R-Square & 1,000 & of Estimate & 0,005177329 \\
\hline & Adhusted R-square & 1,000 & F-statistic & 147,479 \\
\hline Ket & rangan: & & & \\
\hline$x$ & ting ka t suku bun & (Sertif & Bank Indor & \\
\hline Y & perubahan nilai & (kurs) $r$ & ah atas US & \\
\hline Y1 & $\mathrm{Y}_{\mathrm{t}-1}$ & & & \\
\hline Y2 & $Y_{t-2}$ & & & \\
\hline $\mathrm{X} 1$ & $X_{t-1}$ & & & \\
\hline$X 2$ & $X_{t-2}$ & & & \\
\hline a & bilangan konsta & & & \\
\hline b & koefisien & & & \\
\hline
\end{tabular}

Dari hasil perhitungan diatas terlihat da ri t-ratio terdapat variabel yang signifikan ya kni pada va riabel $X$ denga $n t$ hitung 2,535 , va riabel $Y 2$ dengan $t$ hitung 204,058, dan variable $X 2$ denga $n t$ 
hitung 2,737 . Sedangkan variabel tidak signifikan yakni pada variabel $\mathrm{X} 1$ dengan $\mathrm{t}$ hitung 0,974 , va riabel Y1 dengan $t_{\text {hitung }}$ 0,782 ka rena memiliki thitung $<$ dari tabel 2,1009.

Pada model 2 yaitu $X=a$ tbY diasumsikan variabel $Y$ yakni penubahan nilai tukar (kurs) rupiah atas US \$ sebagai variabel independen yang mempenga ruhi varia ble $X$ yakni tingkat suku bunga SBI (Sertifikat Bank Indonesia) sebagai variable dependen. Berdasarkan hasil pengolahan dengan metoda Granger Causality Test (GCT) untuk model 2 adalah seperti yang tercantum pada tabel tiga dibawah ini :

Tabel 2 : Hasil Pengolahan Model 2 GCT

\begin{tabular}{|c|c|c|c|}
\hline \multicolumn{4}{|c|}{$\begin{array}{l}\text { Dependen Variabel is X } \\
18 \text { observation used for estimation from Jan. } 2006 \text { to J un. } 2007\end{array}$} \\
\hline Regresor & & & $\mathrm{t}$ - ratio \\
\hline $\mathrm{Y}$ & & & $-0,561$ \\
\hline $\mathrm{X} 2$ & & & 1,261 \\
\hline Y1 & & & $-0,559$ \\
\hline Y2 & & & 0,348 \\
\hline $\mathrm{X} 1$ & & & 2,621 \\
\hline $\mathrm{R}$ & 1,000 & & \\
\hline R-Square & 1,000 & S.E & \\
\hline Adhusted R-square & 1,000 & $\begin{array}{l}\text { of Estimate } \\
\text { F-statistic }\end{array}$ & $\begin{array}{l}0,038319275 \\
31074,226\end{array}$ \\
\hline
\end{tabular}

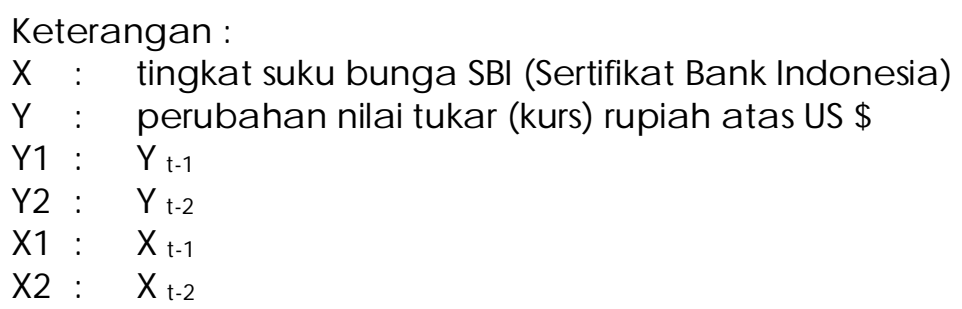

Da ri perhitungan model 2 dia tas hanya ada satu variable thitung yang signifika n ya kni variable $\mathrm{X} 1$ dengan $\mathrm{t}$ hitung 2,621 . Sedangkan va riabel tidak signifikan ya kni pada variabel $\mathrm{Y}$ dengan $\mathrm{t}$ hitung 0,561 , va riabel $X 2$ dengan $t$ hitung 1,261 , va riabel $Y 1$ dengan $t$ hitung 0,559 , da $n$ variabel $Y 2$ dengan $\mathrm{t}$ hitung 0,348 ka rena memiliki $\mathrm{t}$ hitung $<$ dari $\mathrm{t}$ tabel 2,1009 .

Dari kedua model diatas terlihat bahwa model 1 yang lebih banyak signifikannya jika dibandingkan dengan model 2 hal tersebut terbukti dari t-ratio yang dihasilkan dari model tersebut. Dengan demikian dapat dinyatakan bahwa pada periode penelitian, tingkat suku bunga SBI (Sertifikat Bank Indonesia) nyata atau berarti (signifikan) mempengaruhi perubahan nilai tukar (kurs) rupiah atas US \$ sehingga model tersebut dapat diterima karena terbukti secara signifikan atau hal ini terbukti pada tes Granger Causality Test banyak yang signifikan pada $Y=f(x)$ dan tidak seba liknya $X=f(y)$. 


\section{Ana lisis dengan pendekatan Ordinary Least Squa res (OLS)}

Untuk mengetahui seberapa besar variabel independent mempengaruhi variabel dependent, maka dilakukan pengujian mela lui uji ordinary least squares (OLS) berdasarkan pada hasil pengolahan data melalui bantuan program computer (SPSS) dengan menggunakan Analisis Regresi, maka dapat diperoleh adanya suatu pengaruh antara ting kat suku bunga SBI (Sertifikat Bank Indonesia) dengan perubahan nilai tukar (kurs) rupiah atas US \$.

Di dalam analisis model ordinary least squares (OLS) akan dilakukan pengujian yang terdin dari uji signifikan parameter secara individu (uji-t), uji signifikasi parameter secara bersamasama (uji-f), dan uji kesasihan (uji-R2). Dalam melakukan pengolahan data dengan menggunakan ordinary least squares (OLS) mentransformasikan mentanformasikan data kebentuk logaritma. Hasil pengolahan dengan model ordinary least squares (OLS) secara lengkap disajikan dalam table.4 diba wah ini :

Tebel 4 : Hasil Pengolahan Model OLS

\begin{tabular}{|c|c|c|c|c|c|}
\hline \multicolumn{6}{|c|}{ Regression Summa ry for Dependent Variable : Y (new. Sta) } \\
\hline \multirow{3}{*}{$\begin{array}{l}R=0,971 \\
F=266,081\end{array}$} & $R^{2}=0,943$ & & $R^{2}=0,940$ & & \\
\hline & Std. Error of $\epsilon$ & te $=0,0$ & 3199 & & \\
\hline & BETA & $\mathrm{B}$ & Std. Err. of B & $\mathrm{t}$ hitung & Sig. t \\
\hline Interept (c) & - & 9,748 & 0,043 & 228,100 & 0,000 \\
\hline $\mathrm{X}$ & $-0,971$ & $-0,253$ & 0,015 & $-16,312$ & 0,000 \\
\hline
\end{tabular}

Keteragan :

$\mathrm{C}=$ Constant / konstanta

$\mathrm{X}$ = tingkat suku bunga SBI (Sertifikat Bank Indonesia)

Berdasarkan hasil pengolahan data yang telah dilakukan dengan menggunakan SPSS yaitu analsis regresi ordinary least squares (OLS) maka hasilnya secara lengkap dapat dijelaskan sebagai berikut; nilai konstanta da ri persamaan regresi tersebut dia tas adalah negatif yaitu positif 9,748. Hal ini menunjukan apabila pada variabel independent yaitu tingkat suku bunga SBI (Sertifikat Bank Indonesia) sama dengan nol (SBI =0), sehingga variabel perubahan nilai tukar (kurs) rupiah a ta sUS \$ a kan berta mbah sebesar konstanta tersebut.

Pada variabel tingkat suku bunga SBI (Sertifikat Bank Indonesia) memiliki tanda negatif. HaI ini berarti jika terja di kena ikan pada tingkat suku bunga SBI (Sertifikat Bank Indonesia), akan menyebabkan nilai tukar (kurs) rupiah atas US \$ menurun begitupun sebaliknya jika penurunan tingkat suku bunga SBI (Sertifikat Bank Indonesia) maka nilai tukar (kurs) rupiah atas US \$ a kan naik. Hal ini sangat relevan dengan konsistensi teoritis. 
Secara teori hasil regresi ordinary least squares (OLS) pa da variabel suku bunga SBI (Sertifikat Bank Indonesia) memiliki nilai -0,253 yang mempunyai arti bahwa setiap terjadi penununan ting kat suku bunga SBI (Sertifikat Bank Ind onesia), sebesar 1 \% akan menyebabkan nilai tukar (kurs) rupiah atas US \$ naik sebesar 0,253\%. Hal ini terbukti pada nilai t hitung yang cukup signifikan yang akan diuraikan lebih lanjut.

Dari hasil regresi variabel ini memiliki satndar emor 0,005018199 yang relatif kecil, yang berindikasi bahwa ketepatan estimasi mendekati akurat, yang menunjukan bahwa perubahan nilai tukar (kurs) rupiah atas US \$ turut dipengaruhi oleh tingkat suku bunga SBI (Sertifikat Bank Indonesia). Satndar error menunjukan penyimpangan - penyimpangan regresi yang tejadi dalam pegolahan data. Dari hasil penelitian diperoleh angka - angka standar emor yang relatif kecil sehingga dapat disimpulkan bahwa penyimpangan penimpangan regresi dalam penelitian merupakan penelitian kecil yang tidak berpengaruh terhadap setiap variabel, karena semakin kecil standar emor, akan semakin baik hasil perhitungan tersebut.

Dari hasil pengolahan diatas, jika dihubungkan dengan penyimpangan doktrin perubahan nilai tukar. Maka teori nilai tukar mengajarkan argumen yang sederhana namun menyakinkan bahwa nilai tukar menupakan instrumen konvensional untuk mengendalikan atau menekan laju pertumbuhan tingkat inflasi hal tersebut terlihat dari banyaknya jumlah uang beredar di masyarakat. Oleh karena itu penetapan tingkat suku bunga harus benarbenar relevan agar bias merangsang penarikan jumlah uang berdar di ma sya rakat.

Uji-t dilakukan untuk mengetahui berarti tidaknya suatu variabel penjelas dalam mempengaruhi variabel tidak bebas. Apabila nilai $t$ hitung lebih besar dari $t$ tabel, maka penga ruh tersebut signifikan. Untuk mengeta hui besamya pengaruh tingkat suku bunga SBI (Sertifikat Bank Indonesia) terhadap perubahan nilai tukar (kurs) rupiah atas US \$ pada taraf nya ta $(a)=0,05$ atau tingkat kepercayaan untuk menguji hipotesis dengan tingkat derajad kebebasan 18 maka nilai $t$ tabel adalah 2,1009. Dari hasil uji-t diketahui bahwa tingkat suku bunga SBI (Sertifikat Bank Indonesia) terhadap perubahan nilai tukar (kurs) rupiah a tas US \$ adalah signifikan karena dari hasil pengujian sebagaimana terlihat pada tabel 4, membuktikan bahwa $t$ hitung 16,312 lebih besar dari pada $t$ tabel 2,1009. Hal ini berarti bahwa tingkat suku bunga SBI (Sertifikat Bank Indonesia) mempunyai pengaruh yang signifikan terha dap perubahan nilai tukar (kurs) rupiah a tas US \$.

Uji-f dilakukan untuk mengetahui apakah data varibel independent secara keselunuhan mempengaruhi data variabel dependen atau tidak. Apabila $f$ hitung lebih besar dari $f$ tabel, maka variabel data independent secara keseluruhan mampengaruhi variabel data 
dependen. Dari data diperoleh f-tabel-statistik a dalah $(2,18)$ dimana degree of freedom for numerator adalah 2 dan degree of freedom for denominator adalah 18 dimana pada tabel diperoleh 6,01. Maka Fhitung 266,081 > Ftabel 6,01. Hal ini berarti bahwa variabel independen mempengaruhi va riabel dependen.

Nilai $R^{2}$ menunjukan sebarapa besar variasi variabel independent mempengaruhi variasi variabel dependen. Nilai $R^{2}$ ( $R$ - Squared) berkisar antara 0 dan 1 . semakin besar $R^{2}$ berarti semakin besar variasi variabel dependen yang dapat dikelaskan oleh variasi variabel independent, sebaliknya semakin kecil nilai $\mathrm{R}^{2}$ berarti semakin kecil variasi variabel dependent yang dapat dijelaskan oleh variasi variabel independent. Dari tabel 4 pengolahan data diperoleh $\mathrm{R}^{2}$ (R-squared) adalah 0,943 artinya bahwa variasi variabel independen yakni tingkat suku bunga SBI (Sertifikat Bank Indonesia) mempengaruhi variasi variabel dependen yakni perubahan nilai tukar (kurs) nupiah atas US \$ sebesar 94,30\% dengan kata lain selama 18 bulan penelitian yakni dari Januari 2006 sampai dengan Juni 2007 94,30 \% penubahan nilai tukar (kurs) rupiah atas US \$ dipenganuhi oleh tingkat suku bunga SBI (Sertifikat Bank Indonesia), dan 5,70 \% dipenga ruhi oleh va riabel la in diluar model ini, jumlah uang beredar, Jaminan Impor (import guagratee deposits / IGD), Aktiva Luar Negeri Bersih (net foreign assets / NFA), Aktiva Bersih La innya (net other items / NOI), Selisih antara Tagihan Bersih Pada Pemerintah dengan Tagihan Bersih pada Lembaga dan Pusat Pemerintah (net Claims gross / NCG), Tagihan Pada Penusahaan Swasta dan Perseorangan (claims on private enterprise and individuals / CPI) dan beredamya jumlah uang palsu yang tidak terkontrol dengan baik.

\section{KESIMPULAN DAN SARAN}

Hasil analisis Granger Causa lity Test (GCT) menyatakan bahwa selama periode penelitian, tingkat suku bunga SBI (Sertifikat Bank Indonesia) nyata atau berarti (signifikan) mempengaruhi perubahan nilai tukar (kurs) rupiah atas US \$ sehingga model $Y=a+b x$ dan $\mathrm{X}=\mathrm{a}+$ by dapat diterima ka rena terbukti signifikan.

Hasil a na lisis Ordinary Least Squa re (OLS) membuktikan bahwa tingkat tingkat suku bunga SBI (Sertifikat Bank Indonesia) secara signifikan mempengaruhi perubahan nilai tukar (kurs) rupiah atas US \$selama periode penelitian. Hal ini terlihat dari $t$ hitung $16,312>t$ tabel 2,1009. Besa mya R2 (R-Square) adalah 0,943 yang berarti bahwa selama periode penelitian 94,30\% ting kat suku bunga SBI (Sertifikat Bank Indonesia) mempengaruhi perubahan nilai tukar (kurs) rupiah atas US \$ dengan kata la in 5,70\% perubahan nilai tukar (kurs) rupiah atas US \$ dari J anuari 2006 - J uni 2007 dipenga ruhi oleh faktor la in. 
Setelah diambil beberapa kesimpulan, maka selanjutnya peneliti memberikan saran yang berhubungan dengan masalah ini, sebagai berikut : ka rena tingkat suku bunga SBI (Sertifikat Bank Indonesia) mempunyai pengaruh negatif terha dap perubahan nilai tukar (kurs) rupiah atas US \$. Oleh karena itu, sebaiknya pemerintah dapat mempertahankan dan mengoptimalkan instrumen yang ada. Dengan begitu kondisi moneter dapat lebih dikenda lika n dan stabilitasnya tetap terjaga.

\section{DAFTAR PUSTAKA}

Ahmad Jamli, 2004; Dasa r-dasar Keuangan Intema sional, Edisi Pertama, Yogyakarta, BPFE Yogya karta.

Anna D. Martin, 1999., Exchange Rate Exprosure of the Key Financial. Intemational Riview of Economic sand Finance, 9 (2000) : 267-286.

Bank Indonesia, http://www.bi.go.id

Boediono, 2001., Ekonomi Makro Seri Sinopsis Pengantar Ilmu Ekonomi, Edisi Keempat, Yogya karta, penerb it BPFE.

Cho, Dongchul, 2004., Interest Rate, Inflation, and Houshing Price ; With En Emphasis on Chonsei price in Korea, Korea, Development Institude.

I G uustingurah Agung, 2001., Statistika Analisis Hubungan Ka usal Berda sarkan Data Kategorik, Jakarta ,PT. Raja Grafindo Persada.

Nopinin Ph.D, 1992., Ekonomi Moneter, Yogyaka rta, penerbit BPFE.

Paul R. Kurgman dan Maurice Obstfeld (2003) Ekonomi Intemasional Teori dan Kebijakan, Edisi Kedua, J akarta, PT. Raja Grafindo Persa da.

Sudjana, 1993., Statistika Untuk Ekonomi dan Niaga II, Edisi Baru, Bandung, Tarsito. 